\title{
A Derived Piston Configuration to Encourage the Transfer of Residual Gas Fraction to Unite Motor Execution
}

\author{
Dr. Mohammad M. AlAzzawi ${ }^{1}$ MSc. Muayyad Abdulhameed Al-Hayali ${ }^{2}$ MSc. Kousay Nafia Al-Ane ${ }^{3}$ \\ Professor $^{12}$ and Associate Professor ${ }^{3}$ \\ Air-Conditioning Engineering Department \\ Al-Rafidain University College \\ Iraq, Baghdad
}

\begin{abstract}
As motors have created consistently, pistons have progressed with them. They're getting shorter and lighter and use more diminutive skirts the round and hollow "body" of the pistons. More up and coming pistons are consistently made of aluminum compounds included more silicon than previously. This improves insurance from the warmth and diminishes warm advancement [1]. One of the best movements in piston advancement is the usage of different piston "crowns" the part that enters the consuming chamber and is presented to interior burning. While increasingly prepared piston tops were the generally social butterfly, various by and by incorporate dishes on top that incorporate diverse influence the consuming system. In this paper, it presents the distinctive state of piston head "Crown" that can clear up the remaining gas grating to begin choppiness to get a legitimate air-fuel proportion [2,3].
\end{abstract}

Key Words: Residual Gas Friction, Pistons Shape, Burning Procedure, Internal Combustion Motor (I.C. Motor).

\section{INTRODUCTION}

When we're talking about motors, we as often as possible state something is a "four chamber" or a "six barrel." But what does that incredibly mean exactly. For those not familiar with essentials of motor, a "chamber" is the space in which a piston adventures, and pistons are significant parts inside most motors driven by interior burning [4]. Basically, gas and air join in the start chamber over a piston. Right when an electrical begin contacts off that mix, it makes a little impact that drives the piston upward and descending. That improvement turns a crankshaft, which is in the end responsible for driving a transmission and the wheels. Pistons are presented to more warmth, weight and development than about some other motor parts. They should be worked for durability. With motors continually propelling, vehicle makers keep discovering better ways to deal with developed better pistons, including changing their size and structure. The piston is at the center of how motor makes development. Adding pistons to an engine or making them more noteworthy grows dislodging, which suggests the motor making more power since it devours more gas. The amount of pistons in an engine isn't the principle basic thing about them, in any case. The structure of a piston basically influences the inside consuming system [5]. Dominatingly, the condition of a piston has a lot to do with how warm and the air/fuel mix are supervised. This paper presents new state of piston that may help disposing of leftover gas grating so it can prepare for the new air entering the gulf without being blended with the unfortunate gas remaining.

\section{MAIN I.C. MOTOR COMPONENTS}

An internal combustion motor is a glow motor in which consuming (expending of fuel) occurs inside the chamber of the motor. A high temperature and weight drive make ensuing to devouring of fuel. This weight compel use to move the vehicle or turn wheels by usage of some instrument. In motor various parts participate to achieve the goal of changing over substance imperativeness of fuel into mechanical essentialness. These parts are impacted together and the blend of all these parts is known as motor. In this segment we will present some of I.C. Motor parts (segments) that in direct worry with our work. 


\subsection{Cylinder Block}

Cylinder is the essential assemblage of IC motor. Cylinder is a segment in which the affirmation of fuel, weight of fuel and expending of fuel occur. The essential limit of cylinder is to deal with the piston. It is in direct contact with the consequences of consuming so it must be cooled. For cooling of cylinder, a water coat (for liquid cooling used in most of vehicles) or sharp edge (for air cooling used in most of cruisers) are orchestrated at the outside side of cylinder. At the upper end of cylinder, cylinder head and at the base end torque case is impacted. The upper side of cylinder is containing a start chamber where fuel expends. To manage this weight and temperature made by consuming of fuel, cylinder material should have high compressive quality Figure (1). High review of iron cast must be utilized. It is made by tossing and regularly cast in one piece.

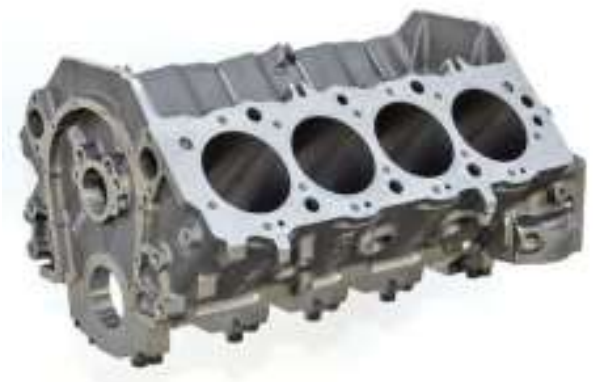

Figure (1): Cylinder Block

\subsection{Piston}

A piston Figure (2) is fitted to each cylinder as a face to get weight of gas and transmit the push to the associating bar, motor prime mover. The standard of piston is to give tight seal to the cylinder through bore and slide uninhibitedly inside the cylinder. Piston should be light and enough strong to manage gas weight created by consuming of fuel. Along these lines, the piston is made by aluminum composite and a portion of the time it is made by cast press since light compound piston spread more than cast press, so they require more clearances to the drag.

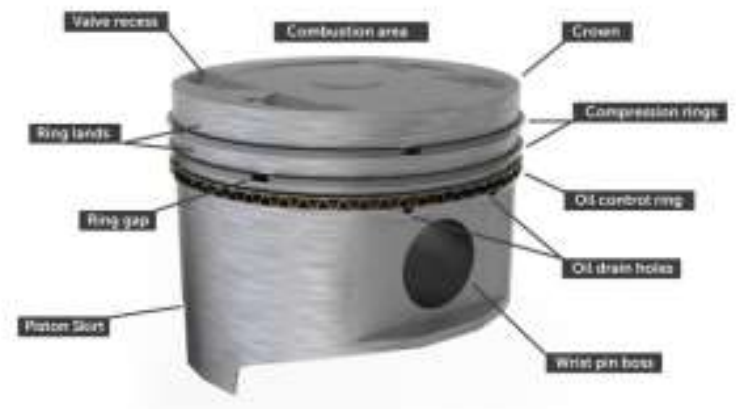

Figure (2): Piston

\subsection{Piston Rings}

A piston must be a free fit in the cylinder so it can move uninhibitedly inside the cylinder. If the piston is unreasonably tight fit, it would spread as it got hot and might stick tight in the cylinder and in case it is too free it would discharge or releases the vapor weight. To give a good settling fit and less grinding restriction between the piston and cylinder, pistons are equipped with piston rings Figure (2). These rings are fitted in scores which have been cut in the piston. They are part toward one side so they can broaden or slipped over the completion of piston.

\subsection{Connecting Rod}

Associating rod Figure (3) interfaces, the piston to crankshaft and transmits the development and push of piston to crankshaft. It changes over the reacting development of the piston into rotational development of crankshaft. There are two closures of interfacing rod; one is alluded to as large end and distinctive as little end. huge end is related with the crankshaft and the little end is related with the piston by use of piston stick. The interfacing rods are made of nickel, chrome, and chrome vanadium steels. 


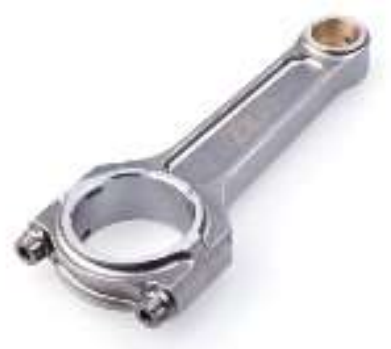

Figure (3): Connecting Rod

\subsection{Crankshaft}

The crankshaft Figure (4) of I.C motor gets the undertakings or push given by piston to the interfacing rod and changes over the reacting development of piston into turning development of crankshaft. The crankshaft mounts in bearing so it can rotate wholeheartedly. The shape and size of crankshaft depends upon the number and strategy of cylinders. It is commonly made by steel fabricating, yet a couple of makers use one of a kind sorts of give iron such a job as spheroidal graphitic or nickel combination castings which are more affordable to produce and have extraordinary obligation life.

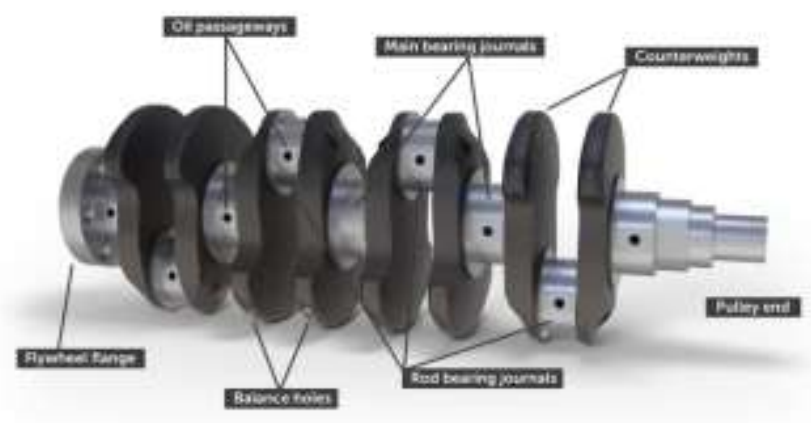

Figure (4): Crankshaft

\subsection{Spark Plug}

It is used in begin motor. The major capacity of a start plug is to coordinate a high potential from the begin framework into the consuming chamber to light the compacted air fuel mix. It is fitted on cylinder head. The start plug involves a metal shell having two electrodes which are shielded from each other with an air gap. Right when high potential current supply to begin plug it bouncing from the supply electrode and produces the generous start Figure (5).



Figure (5): Spark Plug

\subsection{Fuel Injector}

Injector is commonly used in pressure begin motor. It showers the fuel into consuming chamber toward the completion of pressure stroke. It is fitted on cylinder head Figure (6). 


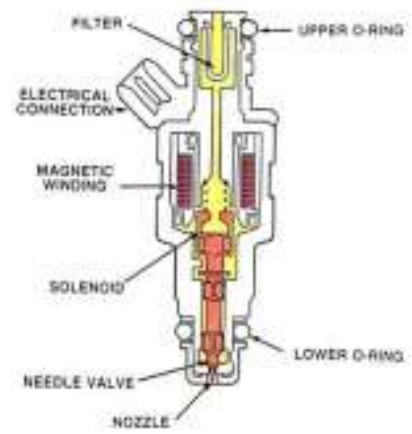

Figure (6): Fuel Injector

\subsection{Manifold}

The principal usefulness of complex is to supply the air fuel blend and accumulates the fumes gases comparatively from all cylinder. In an inside ignition motor two manifolds are used, one for admission and other for fumes. Aluminum amalgam is the principle material of complex Figure (7).

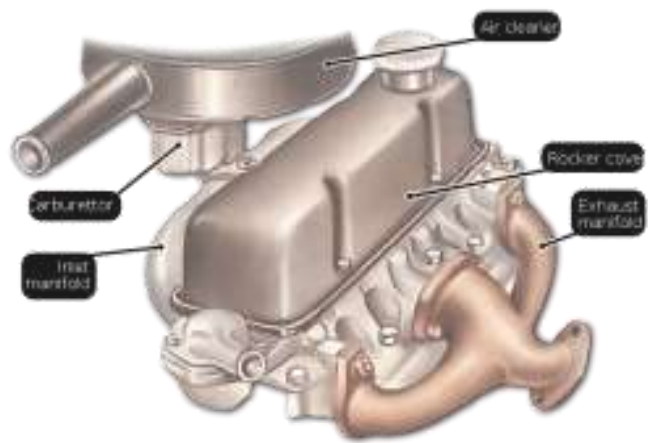

Figure (7): Full Engine Review Clarifying Manifold On The Bottom Right End

\section{PROPOSED PISTON DESIGN}

As referenced over the unwanted gasses may put down a portion of the motor execution this paper present a state of piston head "Crown" to begin disturbance to get a legitimate air fuel proportion and it might even diminish fuel utilization as expressed in Figure $(8,9)$ which the proposed piston configuration is like triangle in the piston go to clear up however much remaining gas grating as could reasonably be expected improving the choppiness and motor execution.

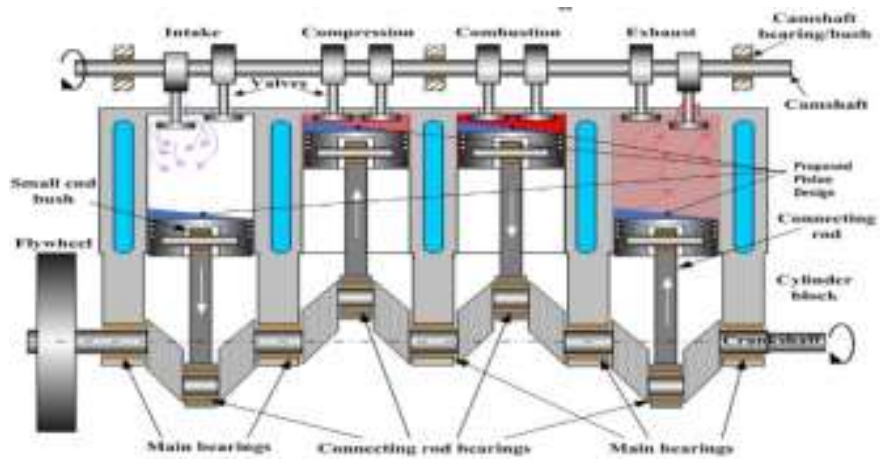

Figure (8): Proposed Piston Design

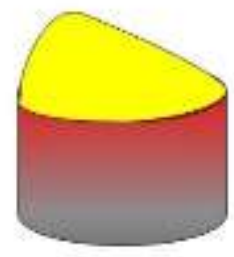

Figure (9): Simple Piston Design 


\section{REFERENCES}

[1] Carley, Larry. "Piston Design, an Evolutionary Tale." Engine Builder Magazine. April 1, 2003. (Dec. 7, 2011) http://www.enginebuildermag.com/Article/1948/piston_design_an_evolutionary_tale.aspx

[2] CDX Online Textbook. "Motor Components: Pistons." $\quad$ (Dec. 8, 2011) http://www.cdxetextbook.com/motors/comp/pistons/pistons.html

[3] University of Windsor. "Piston $\quad$ Design." $\quad$ (Dec. $\quad 7, \quad 2011)$
http://courses.washington.edu/engr100/Section_Wei/motor/UofWindsorManual/Piston\%20Design.htm

[4] Vegburner. "DI Combustion Chamber Design." (Dec. 8, 2011) http://vegburner.co.uk/DIcombustion.html

[5] https://auto.howstuffworks.com/piston-shape-influence combustion.htm 